\title{
On the mixing-driven formation of the Extratropical Transition Layer (ExTL)
}

\author{
Paul Konopka ${ }^{1}$ and Laura L. Pan ${ }^{2}$ \\ Received 30 March 2012; revised 3 August 2012; accepted 3 August 2012; published 19 September 2012.
}

[1] We present a case study on the formation and structure of the Extratropical Transition Layer (ExTL) using in situ observations and a Lagrangian chemical transport model. The results show that the model with mixing parameterized from the large-scale flow deformations well reconstructs the observed asymmetric structure of the ExTL with a deeper transition layer on the cyclonic side of the jet stream. Information from the model and observations are integrated using tracer-tracer correlations between ozone $\left(\mathrm{O}_{3}\right)$ and carbon monoxide (CO). Transport of chemical tracers from the stratospheric or tropospheric background to the ExTL through mixing is identified by the change of the $\mathrm{CO}-\mathrm{O}_{3}$ correlation in the $\mathrm{CO}-\mathrm{O}_{3}$ space. The ExTL formation process simulated by the model, therefore, provides a scenario to connect the mixed air parcels to the history of mixing. An estimate of timescales of ExTL formation is made using model experiments. The results show that the fastest formation of the ExTL occurs on the isentropic levels below the subtropical jet core, e.g. around 3 weeks for $310 \mathrm{~K}$, whereas at $360 \mathrm{~K}$ level (jet core) the formation of the ExTL needs around 3 months. Overall, this result demonstrates the important role of mixing in transport of trace gases across the tropopause.

Citation: Konopka, P., and L. L. Pan (2012), On the mixing-driven formation of the Extratropical Transition Layer (ExTL), J. Geophys. Res., 117, D18301, doi:10.1029/2012JD017876.

\section{Introduction}

[2] Mixing is an important physical process transporting chemical constituents and a key mechanism for irreversible stratosphere-troposphere exchange. Signatures of mixing in the tropopause region are frequently observed by in situ trace gas measurements, often revealed in tracer-tracer correlations as "mixing lines" [e.g., Hintsa et al., 1998; Fischer et al., 2000; Hoor et al., 2002; Marcy et al., 2004]. Frequent mixing of stratospheric and tropospheric air in the vicinity of the tropopause forms a transition layer, termed as the Extratropical Transition Layer (ExTL) [World Meteorological Organization, 2003; Pan et al., 2004; Hegglin et al., 2009]. Representing the ExTL and quantifying mixing processes in general has been a significant challenge for models [e.g., Hegglin et al., 2010]. In this work, we demonstrate a successful model representation of the ExTL using a Lagrangian model and aircraft in situ observations. This allows us to connect the mixing process itself with the resulting structure of the ExTL.

[3] Although mixing at the molecular scale is accomplished by small-scale processes such as turbulence and molecular diffusion, the stirring and stretching of the large-

\footnotetext{
${ }^{1}$ IEK-7: Stratosphere, Forschungszentrum Jülich, Jülich, Germany.

${ }^{2}$ NCAR, Boulder, Colorado, USA.

Corresponding author: P. Konopka, IEK-7: Stratosphere, Forschungszentrum Jülich, DE-52425 Jülich, Germany. (p.konopka@fz-juelich.de)

C2012. American Geophysical Union. All Rights Reserved. 0148-0227/12/2012JD017876
}

scale flow increases the spatial gradients of trace substances and thereby reduces timescales for mixing [Juckes and McIntyre, 1987; Pierrehumbert, 1991; Scott and Cammas, 2002; Bowman et al., 2007]. Processes driving mixing itself are small-scale vertical or horizontal instabilities in the flow (e.g. Kelvin-Helmholz instability) which are not resolved by the global models. Following the idea of the gradient Richardson number $R i$, which is an indicator for hydrostatic instabilities [Turner, 1973], mixing is expected to be triggered not only by deformations in the flow such as stirring or stretching, but also by convective instabilities. The conditions of low static stability, i.e., $d \theta / d z \sim 0$, is a significant contributor to mixing in the troposphere [Jeager and Sprenger, 2009].

[4] Another way to find out the flow parameters which drive mixing is to use the so-called diffusive reconstruction of the observed chemical tracers [Legras et al., 2005]. The main idea of this procedure is to extend the trajectory equation to a stochastic equation with random force describing turbulence that is parameterized, typically as a white noise process. This random force stochastically changes the backward trajectories of the air parcels launched from the observation point and imitates the impact of mixing. By considering an ensemble of trajectories and by using a lowresolution chemistry-transport model (CTM), the observed mixing ratios of passive tracers are then reconstructed through a simple averaging over all end points of the trajectory ensemble where the end points values are provided by interpolation from the CTM. Regions of the atmosphere where random force imitates turbulence are expected to be 
dynamically unstable, i.e. are characterized by high shear/ strain rates or/and low vertical stability.

[5] However, Lagrangian transport as modeled in this paper is a forward (in time) view of irreversible transport, i.e. inherently containing the concept of mixing. Here, we use the CLaMS (Chemical Lagrangian Model of the Stratosphere) assuming that there is a connection between the large-scale stratospheric flow on a spatial scale of the order $100 \mathrm{~km}$ and mixing.

[6] One of the primary goals of this study is to show that this large-scale-based mixing scheme can also represent the main features of the ExTL. Because mixing is an accumulative process integrating in time, the observed time series of the chemical composition alone does not provide direct evidence of when and where the relevant mixing events have happened. Here, we discuss how the model helps connect the signatures of mixing observed in the $\mathrm{CO}-\mathrm{O}_{3}$ correlations to the flow configurations upstream.

[7] We also show how on a synoptic timescale of only several days, the large-scale, quasi-isentropic flow deformations form a significant part of the ExTL around the jet, especially the layer on its adjacent cyclonic side. Finally, we discuss a method of estimating the timescale of ExTL formation.

\section{Model Description}

[8] The CLaMS model is an adaptive grid Lagrangian chemistry transport model that implements the concept of large-scale flow deformation-induced mixing. The model uses an ensemble of air parcels to serve as a time-dependent irregular grid. The positions of these parcels at a given time are determined by 3-D trajectory calculations. Unlike other trajectory models that use pure advection, CLaMS allows these parcels to mix, resulting in a change in the chemical composition of the parcels. The mixing is controlled by a physically based mechanism using the local horizontal strain and vertical shear rates of the wind fields. In particular, the model couples the large-scale flow deformations $\gamma=\lambda \Delta t$, measured in terms of the Lyaupunov exponent $\lambda$ and the advective time step $\Delta t$ along the trajectory, with the mixing processes between the Lagrangian air parcels [McKenna et al., 2002; Konopka et al., 2004].

[9] In practice, the integral deformations $\gamma$ captures both horizontal (mainly strain) and vertical (mainly shear) deformations in the flow and can be derived from the relative motion of the next neighbors. In the stratosphere and in the large parts of the UTLS, where the flow is characterized by a high static stability, only sufficiently strong deformations with $\gamma>\gamma_{c}\left(\gamma_{c}\right.$ denoting an empirical critical deformation) are expected to trigger mixing. This concept was validated by comparing CLaMS results with the observed tracer-tracer correlation and time series [Konopka et al., 2004] with the best choice for $\gamma_{c}$ between 1 and 1.5. Using the same parametrization of mixing, the model was extended to the troposphere [Konopka et al., 2007; Vogel et al., 2011].

\section{ExTL Above North America in April 2008}

[10] Our case study examines the structure and formation of the ExTL observed during the Stratosphere-Troposphere Analyses of the Regional Transport 2008 (START08) experiment, research flight 4 (RF04), on April 28th, 2008 [Pan et al., 2010]. Figure 1 shows the synoptic scale meteorological conditions sampled by the Gulfstream V (GV) research aircraft, $\mathrm{CO}-\mathrm{O}_{3}$ correlation from the in situ measurements during this flight, and vertical cross-section sampled during the flight with the ExTL identified by the $\mathrm{CO}-\mathrm{O}_{3}$ relationship. The ExTL is defined in $\mathrm{CO}-\mathrm{O}_{3}$ space (Figure $1 \mathrm{~b}$, gray) by separating mixed air parcels from tropospheric (blue) and stratospheric (orange) branches using criteria discussed in Pan et al. [2010]. We highlight here the asymmetric structure of the ExTL as a key feature, with a deeper transition layer on the cyclonic side of the jet. This structure is consistent with previous observations using $\mathrm{H}_{2} \mathrm{O}-\mathrm{O}_{3}$ correlation [Pan et al., 2007] and is a robust feature.

[11] To investigate the processes which create the observed signatures, CLaMS simulations of $\mathrm{CO}$ and $\mathrm{O}_{3}$ were carried out. We use a multiannual run from 2001 to 2010 driven by the ECMWF analysis covering the entire troposphere and stratosphere between the Earth's surface and the stratopause at $\theta \approx 2500 \mathrm{~K}$ potential temperature level [Konopka et al., 2010]. Starting from April 2008, the horizontal and vertical resolution of this run were increased to $\sim 75 \mathrm{~km}$ and $300 \mathrm{~m}$, respectively, near the tropopause. Ozone is transported as a passive tracer prescribed by the HALOE climatology above $500 \mathrm{~K}$ and set to zero at the Earth's surface. CO values retrieved by the Atmospheric Infrared Sounder (AIRS) on the NASA Aqua satellite are used to prescribe $\mathrm{CO}$ sources at the Earth's surface as described in Vogel et al. [2011]. The chemical lifetime of $\mathrm{CO}$ in the model is around 3 month.

[12] The comparison between observations and the model is shown in Figure 2. The time series and $\mathrm{CO}-\mathrm{O}_{3}$ correlation are in Figures $2 \mathrm{a}$ and $2 \mathrm{~b}$, respectively. Note that the model output is at the synoptic date/time of April 28th, 18 UTC and has a horizontal spatial resolution of $\approx 75 \mathrm{~km}$. Observations, on the other hand, were made during $\approx 8$ hours of flight on a spatial scale of $\approx 250 \mathrm{~m}$. To compare the model with observations, we use forward and backward trajectories to transform the (asynoptic) GV observations to April 28th, 18 UTC. Furthermore, $\mathrm{CO}$ and $\mathrm{O}_{3}$ values at the next neighbors in CLaMS irregular grid were used with the consequence that the number of available CLaMS air parcels is significantly smaller compared with that of observations (within the ExTL the ratio of the observed to the CLaMS air parcels is given by $\sim 20: 1$ ).

[13] Despite such differences in sampling, CLaMS represents qualitatively the observed ExTL (Figure 2). In the physical space (Figure 2a), CLaMS simulations represent the observed CO and ozone time series well. More importantly, Figure $2 \mathrm{~b}$ also shows that the model represents the mixing lines reasonably well in their location in the tracer space.

\section{Diagnostic of Mixing}

[14] To investigate the frequency, timescales and history of mixing, three diagnostics are applied. The first one is a back trajectory analysis in conjunction with the CLaMS run, performed to quantify the mixing experienced by the air parcels relevant to the observed ExTL. Specifically, 3-day back trajectories are calculated for all parcels at the vertical cross-section of GV sampling, initiated on April 28th, 18 UTC (Figure 1c). We represent this cross-section by a $2 \mathrm{D}$ grid 

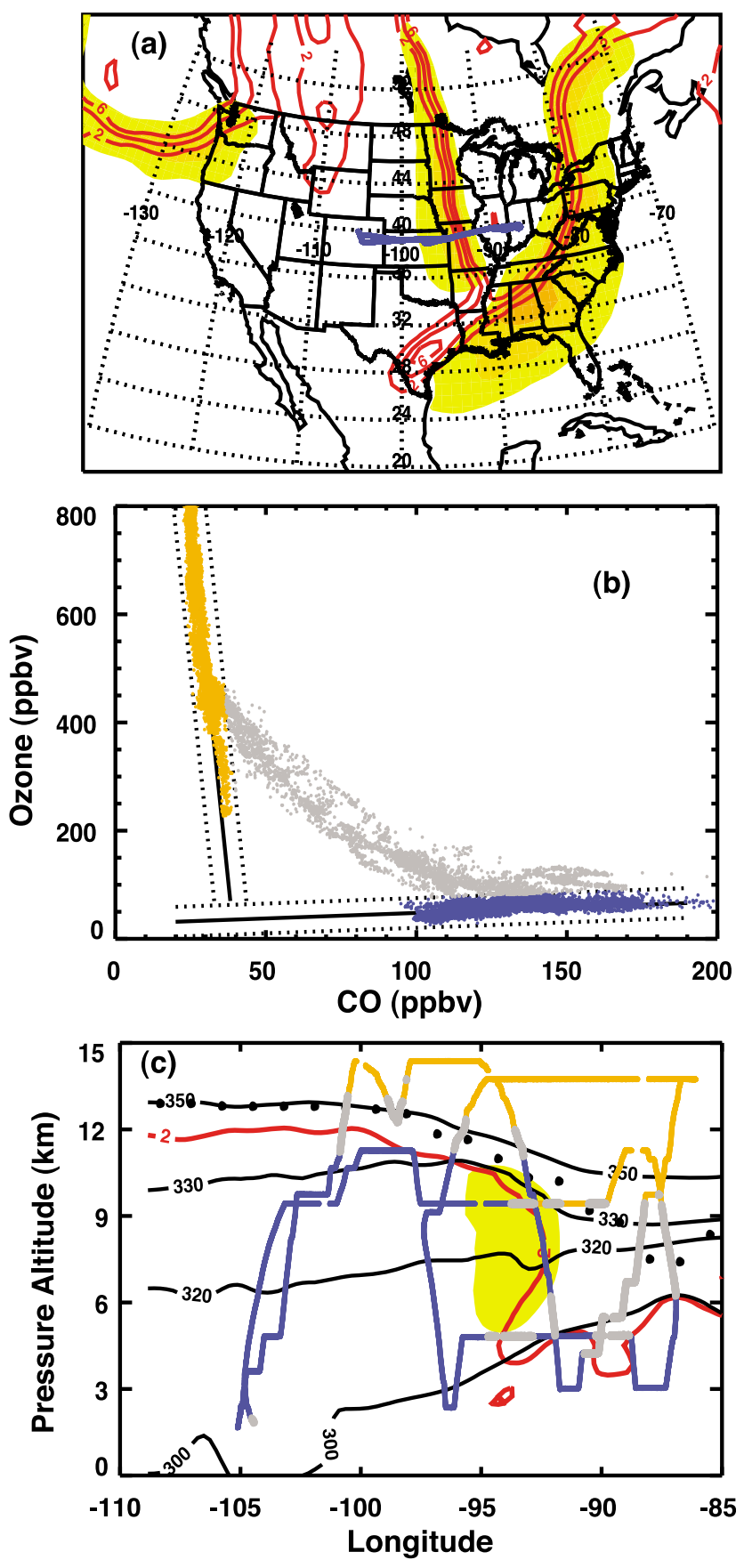

Figure 1. (a) Synoptic scale meteorological situation during START08, on April 28th, 2008, is represented by jet stream locations (wind speed on $300 \mathrm{hPa}$, yellow shading shows 40,50, and $60 \mathrm{~m} / \mathrm{s})$, PV (2, 4, 6 PVU, red contours). The ground track of the research aircraft Gulfstream V $(\mathrm{GV})$ is marked by the blue line (roughly along $40^{\circ} \mathrm{N}$ from Colorado to Indiana). (b) The observed $\mathrm{CO}-\mathrm{O}_{3}$ relationship is used to identify the background (blue and orange for the tropospheric and stratospheric branches, respectively) and the ExTL (gray). (c) The GV track is colored with the correlation-based classification of the air masses as shown in Figure 1b. The position of the jet core is shown in yellow shading $(>50 \mathrm{~m} / \mathrm{s}$ wind speed). The thermal tropopause (black dots), the 2 PVU contour (red) and selected isentropes (black lines) are also shown. with horizontal and vertical resolution given by $25 \mathrm{~km}$ and 3 $\mathrm{K}$ potential temperature, respectively.

[15] Along each 3-day back trajectory with a 6 hour time step, we record all the mixing events the neighboring CLaMS parcels have experienced. This information quantifies how often the parcel's mixing ratios are changed by the mixing algorithm. Thus, the frequency of mixing along each trajectory is defined as a percentage (\%) of the 6 hour steps when the CLaMS nearest neighbor experienced mixing. The 3 -day frequency of mixing for the cross-section is shown in Figure 3 (only values $>50 \%$ ).

[16] A second diagnostic investigates the evolution of the correlation-based classification of the air parcels. In this case, the same 3-day back-trajectories as described above are used to connect and compare the location of air parcels in the $\mathrm{CO}-\mathrm{O}_{3}$ space. This comparison identifies the change of each parcel's air mass classification during the last 3 days (i.e. stratospheric, tropospheric or ExTL (Figure 4, left)). Thus, Figure 4 shows the ExTL generated by the CLaMS reference run (dark gray) at the synoptic time closest to the observation (April 28th, 18 UTC), and also regions which had belonged to the ExTL on April 25th but have become a part of the stratospheric or tropospheric background on April 28th (orange indicates the region where air masses changed from the ExTL-to-stratosphere, i.e. ExTL-S, and light blue for the ExTL-to-troposphere, i.e. ExTL-T). These three parts of the vertical cross-section mark the region significantly altered by mixing that is also schematically shown in the tracer space in Figure 4 (left). Note that in this way we extend the conventional notation of the stratosphere-troposphere exchange processes (STE) to stratosphere-ExTL-troposphere exchange. This concept highlights the role of the ExTL in STE and helps visualizing how chemical transport is accomplished by mixing.

[17] Now we compare in Figure 4 the light gray colored segments of the flight track defining the observed ExTL (i.e. the same segments as in Figure 1c) with the results of our calculations (dark gray, orange and light blue). The comparison shows that some parts of the observed ExTL are not resolved in the CLaMS simulation (light gray segments outside of the dark gray region). This can be due to some differences in sampling (the vertical cross-section and the observations are shifted by several hours) or by some deficiencies in the model. The latter is supported by the backtrajectories indicating a thicker ExTL, mainly on the cyclonic side of the jet around the 2 PVU contour (light blue). However, the asymmetric structure of the ExTL with a deeper transition layer on the cyclonic side of the jet stream is reproduced well by the model. The asymmetric structure of the ExTL relative to the jet also manifests itself in the significant differences between the thermal and dynamical tropopause [Pan et al., 2007].

[18] Because mixing in CLaMS is driven by the deformations in the flow (horizontal strain but mainly vertical shear), the highest values of the frequency of mixing are found in the vicinity of the jet (Figure 3). However, not every CLaMS mixing event renders the parcel in the ExTL. Mixing events between pure tropospheric or stratospheric air parcels contribute to the frequency of mixing but do not change their correlation-based classification. Therefore, the high mixing frequency region in Figure 3 is much larger than the ExTL diagnosed in Figure 4. 

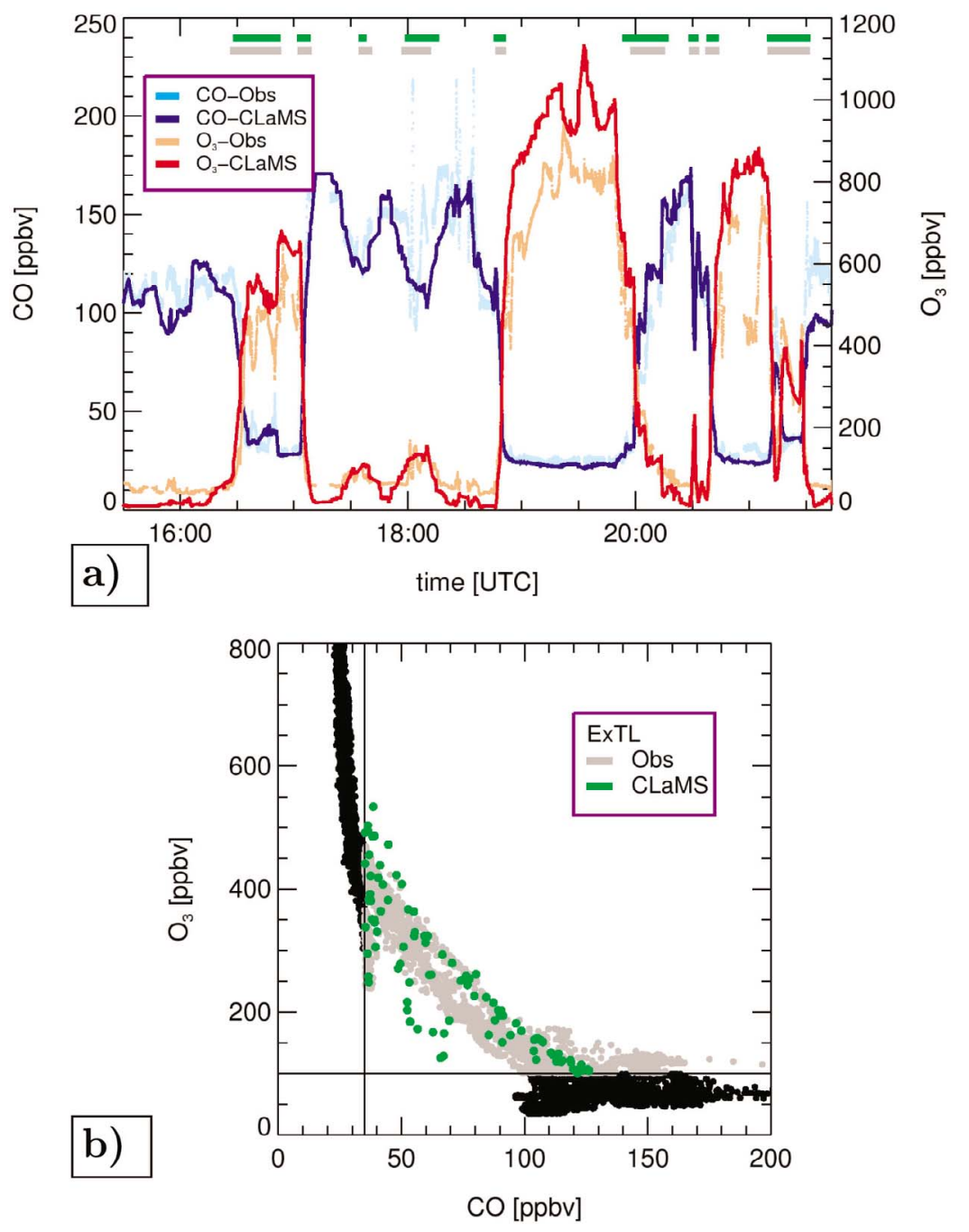

Figure 2. GV observations versus CLaMS simulations (a) for the time series of $\mathrm{CO}$ and $\mathrm{O}_{3}$ and (b) for the $\mathrm{CO}-\mathrm{O}_{3}$ correlations. The ExTL characterized by mixed air parcels is separated from the tropospheric and stratospheric branches by setting $\mathrm{O}_{3}>100 \mathrm{ppmv}$ and $\mathrm{CO}>35 \mathrm{ppbv}$ (black solid lines). The time windows when those (mixed) parcels were sampled or resolved by CLaMS are respectively marked in Figure 2a (gray and green segments).

[19] Now, we characterize the timescale of ExTL formation. As a third diagnostic, we use a 3-day CLaMS simulation with an initial condition of no ExTL. This is done for April 25th, 12 UTC, 3 days prior to the observation, with $\mathrm{CO}$ and $\mathrm{O}_{3}$ initialized in the model by an idealized L-shape correlation, i.e. with either $[\mathrm{CO}]<35 \mathrm{ppbv}$ (pure stratospheric) or with $\left[\mathrm{O}_{3}\right]<100$ ppbv (pure tropospheric, see Figure 2). This artificial separation is done along the tropopause defined by the isentropic PV gradient $[K u n z$ et al., 2011]. Briefly, PV values that mark the maximum isentropic $\mathrm{PV}$ gradient are used as the dynamic tropopause for each isentrope. $\mathrm{CO}$ and $\mathrm{O}_{3}$ mixing ratios of air parcels were assigned to the tropospheric or stratospheric branches accordingly.

[20] Thus, after re-initializing the model with idealized stratosphere-troposphere separation, the air parcels with a mixed $\mathrm{CO}-\mathrm{O}_{3}$ composition constitute a "freshly mixed" subset of the ExTL formed during the 3 days prior to the observation (green hatched part in Figure 4). This freshly formed part contributes to $\approx 50 \%$ of the ExTL calculated in the reference run (green to gray ratio in Figure 4) and to more than $70 \%$ of the ExTL on the cyclonic side of the jet (green to gray ratio for longitudes larger then $-94^{\circ} \mathrm{E}$ in Figure 4). This result shows that a significant part of the ExTL, especially the part on the cyclonic side of the jet, was generated during this short simulation time. In particular, the high values of the frequency of mixing diagnosed in CLaMS below the subtropical jet core (Figure 3, longitudes between -95 and $\left.-87^{\circ} \mathrm{E}, 290 \leq \theta \leq 320 \mathrm{~K}\right)$ reveal the intense mixing activities which contribute to a rapid ExTL formation.

[21] Using this method, we can quantify the timescale of ExTL formation at each isentropic level and for the whole Northern Hemisphere by evaluating the length it takes for the model transport process (advection + mixing) to reproduce the ExTL in the sense that the ratio between the number of mixed air parcels generated in the idealized run reaches $90 \%$ of the reference run (Figure 5). We found that the shortest timescales of ExTL formation are on the isentropic 


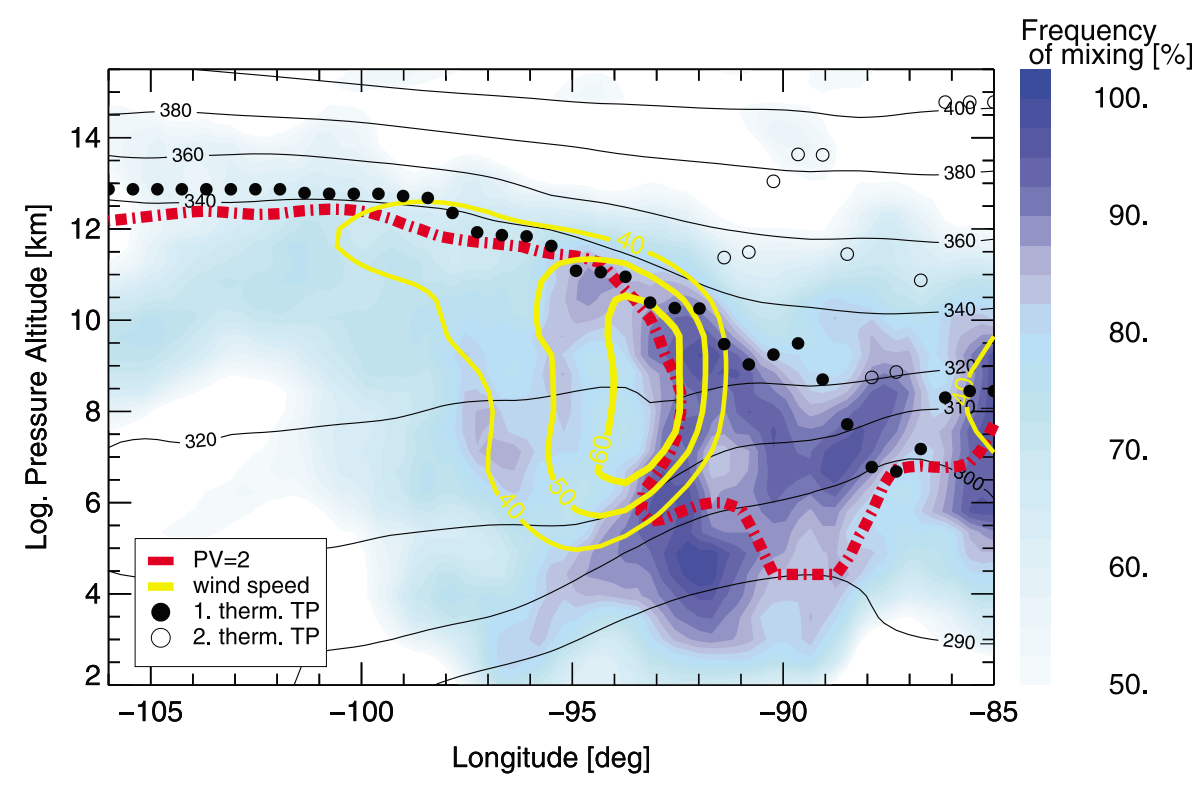

Figure 3. The vertical cross-section sampled by the GV as in Figure 1. The frequency of mixing experienced by the CLaMS air parcels in the cross-section on April 28th, 18 UTC during the last 3 days (blue shadings).

levels below the subtropical jet core, e.g. around 3 weeks for $310 \mathrm{~K}$, whereas at $360 \mathrm{~K}$ level (where the ExTL intersects the jet core) it is around 3 months. This behavior that is in qualitative agreement with the results discussed by James and Legras [2009] indicates much more wave activities below the jet core (baroclinic waves) compared with that at the level of the jet core. The much longer time required to form ExTL at the $360 \mathrm{~K}$ level reflects that mixing is prohibited in the region of the jet core, as shown by numerous previous studies based on the effective diffusivity analysis [e.g., Haynes and Shuckburgh, 2000].

[22] In addition, at a given potential temperature level, longest (shortest) timescales of mixing are diagnosed in regions with high (low) values of $N^{2}$ (green and orange). The largest differences between these two parts were found for isentropes crossing the jet, i.e. for $\theta$ between 320 and $360 \mathrm{~K}$. That means that the tropopause inversion layer (TIL) [Birner et al., 2002] characterized by large values of $N^{2}$ needs

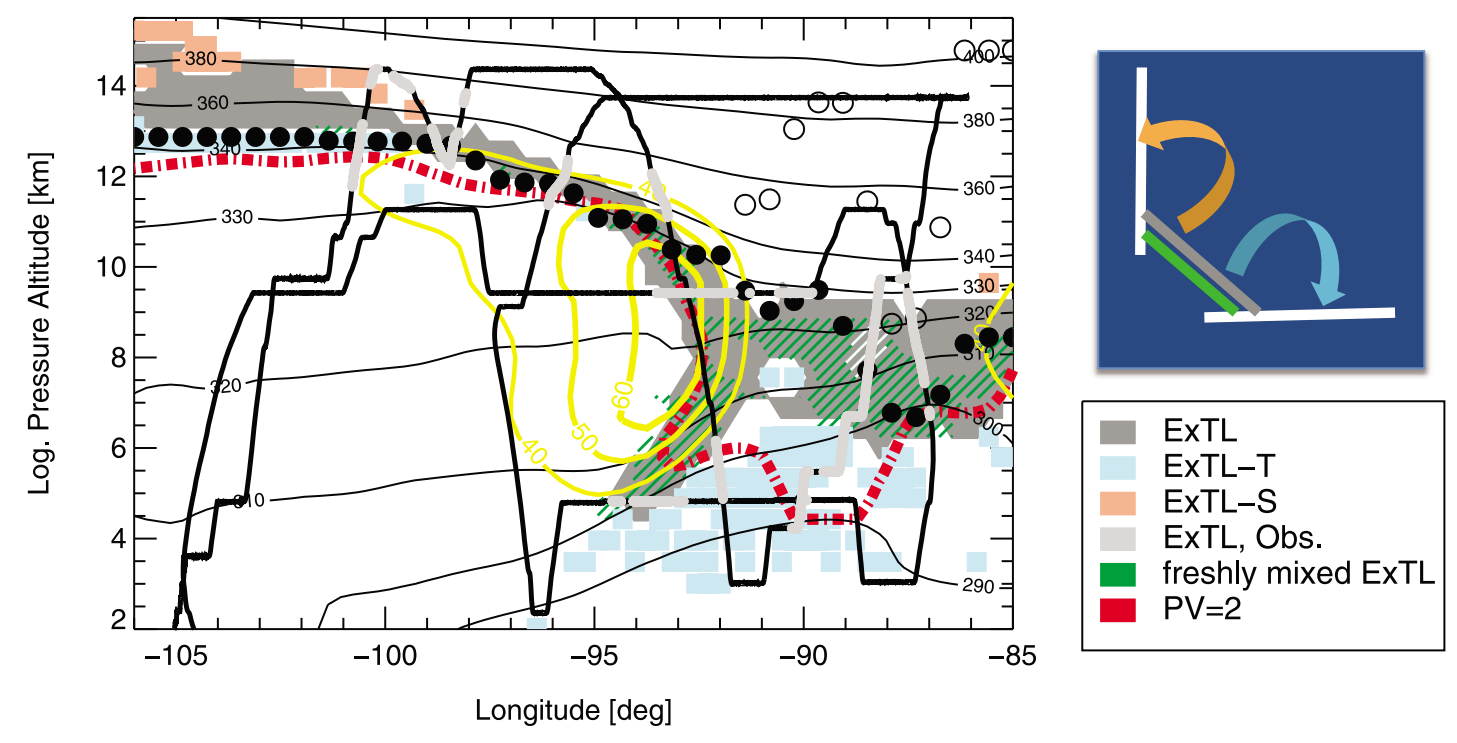

Figure 4. Modeled versus observed ExTL in the same cross section as in Figure 3. ExTL based on CLaMS simulated $\mathrm{CO}, \mathrm{O}_{3}$ from the reference run (dark gray). Additional color shaded regions show where the composition of air changed from the ExTL to stratosphere (orange) and to troposphere (light blue) diagnosed by 3-day back trajectories and CLaMS CO-O $\mathrm{O}_{3}$ correlation (see also schematic diagram on the right). Light gray segments along the flight track denote the observed regions of ExTL (same as in Figure 1c). The freshly mixed region, i.e. the ExTL formed in the last 3 days of the CLaMS simulation, is shown by the green hatching. 


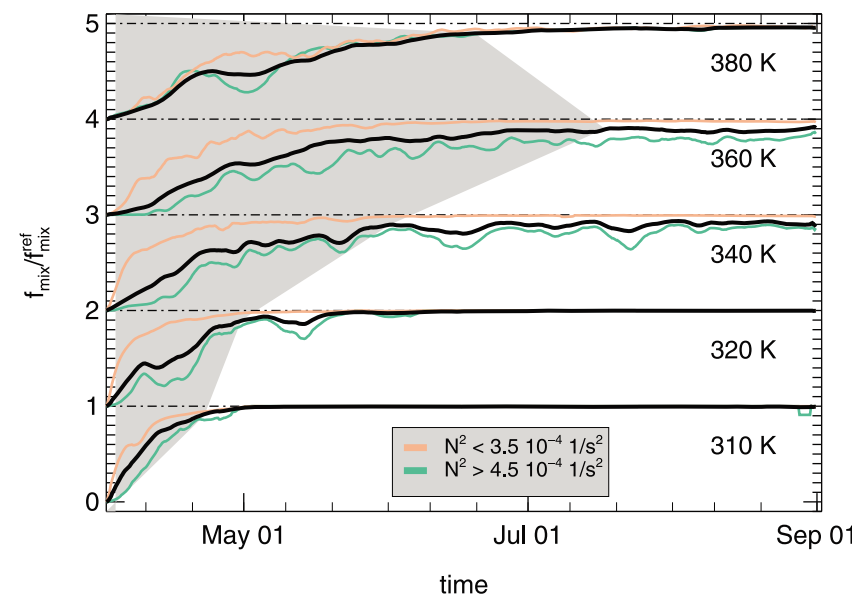

Figure 5. Timescales for the formation of mixing layer at $\theta=310, \ldots 380 \mathrm{~K}$ inferred from the convergence of the ratio $f_{\text {mix }} / f_{\text {mix }}^{r e f}$ to $90 \%$, with $f_{\text {mix }}$ and $f_{\text {mix }}^{r e f}$ denoting the number of mixed air parcels generated in the idealized and the reference run, respectively (black lines). By defining two different subsets of these air parcels, with large and small values of $N^{2}$ (green and orange), the impact of the stability on the formation of the ExTL can also be inferred. The gray colored region connects points with $f_{\text {mix }} / f_{m i x}^{r e f}=90 \%$. The start time of the x-axis is April 1th, 2008 (start of the idealized run) with the minor and major ticks marking 10 days and 2 months intervals, respectively.

significantly more time to be fully reconstructed from our idealized experiment. This finding supports the results of [Kunz et al., 2009] indicating that TIL mainly contains aged mixed air formed rather on seasonal than synoptic timescales. Note that all the mixing times discussed in Figure 5 are mean values related to the whole ExTL on the Northern Hemisphere during the spring-summer season. Locally, as for our case study in the vicinity of the jet, the mixing times are even shorter than one week.

[23] Using the same diagnostic, we now examine the history of ExTL formation from an isentropic perspective. Figure 6 displays how the freshly mixed part of the ExTL develops at the $\theta=310 \mathrm{~K}$ potential temperature surface. According to our re-initialization on April 25th, 12 UTC, with the L-shape $\mathrm{CO}-\mathrm{O}_{3}$ correlation, the first panel shows the perfectly separated stratosphere (orange dashed) from the troposphere by the PV gradient tropopause (approximately 2 PVU in this case). The yellow lines denote the wind isolines $(40,50 \mathrm{~m} / \mathrm{s})$ identifying the position of the jet. Then, during the course of the simulation, the ExTL evolves (gray), mainly on the cyclonic side of the jet. Because at the initialization time some tropospheric air was trapped within the stratosphere, these areas are gradually transformed into the ExTL.

[24] Figure 6 also shows the locations of CLaMS mixing events that contributed to the formation of the ExTL, in the $\theta=310 \pm 3 \mathrm{~K}$ layer, within the 3-day simulation at selected time steps. These locations are identified along the 3-day back trajectories shown as colored dots or squares. Their vertical positions can be inferred from the pressure isolines, also displayed in Figure 6. The very different origins of air, both horizontally and vertically, indicate that potentially very distinct air masses were involved in the subsequent mixing and transport.

[25] The CLaMS diagnostic along the back-trajectories allows to identify when and where the relevant mixing events occurred in the model. If the nearest CLaMS air parcel experienced mixing the violet colored position of the back-trajectory is switched to a cyan square. In addition, if such a mixing event changed the parcel's tracer-correlation based air mass identification from a pure tropospheric or pure stratospheric to ExTL, the cyan mark is replaced by a red mark. Because we do not reset the colors, the air parcels along the back-trajectories gradually change their colors from violet through cyan to red. In this way, time and position of the relevant mixing events for the $\theta=310 \pm 3 \mathrm{~K}$ slice of the ExTL are highlighted (red squares).

[26] This history and evolution provide a CLaMS model perspective of the formation of the ExTL. Although the ExTL is often shown in the vertical dimension, its history of formation, at least a significant part of it in our case study, is quasi-horizontal (i.e. almost isentropic), accumulative and controlled by the flow configuration upstream. Remarkably, almost all these mixing events occur on the stratospheric (cyclonic) side of the jet. Although in reality other processes, such convection, may also contribute to the formation of the ExTL, our case study shows that the large scale stirring dominates the formation of its asymmetric structure.

\section{Discussion and Conclusions}

[27] Mixing is an important process in trace gas transport in the atmosphere. Because of its irreversible character, mixing is an accumulative process that alters tracer distributions in a way that the initial distribution cannot be uniquely reconstructed from their final properties, using observations alone. In this case study, we have demonstrated the utility of an integrated model-observation approach to relate the result of mixing to the large scale flow and to quantify the accumulated effect of mixing on ExTL formation and on transport across the tropopause.

[28] Because the physical processes driving mixing are below the resolution of the currently used global models and are often non-linear physical processes triggered by dynamical instabilities -, appropriate parametrization are necessary. The representation of mixing in CLaMS uses the empirical critical deformation $\gamma_{c}=\lambda_{c} \Delta t\left(\lambda_{c}\right.$ - critical Lyapunov exponent, $1 / \Delta t$ - mixing frequency) to parameterize this process with flow deformations $\gamma>\gamma_{c}$ triggering the mixing algorithm [Konopka et al., 2007]. Albeit in this case study the model successfully represented the observed asymmetric structure of the ExTL near the jet stream, the results also show the weakness of the model. Thus, several critical comments are necessary:

[29] (1) Although mixing in the model driven by large scale deformations represents a significant physical process, there are additional important mechanisms for physical mixing in the UTLS. In particular, convective processes with mixing dependent on static stability $(d \theta / d z)$ are not yet included in the model. (2) According to d'Ovidio et al. [2009], strain - not shear - is relevant for isentropic mixing. This has implications for the definition of the critical deformation $\gamma_{c}$. (3) Elimination of numerical deficiencies in the determination of the next neighbors, as recently pointed 

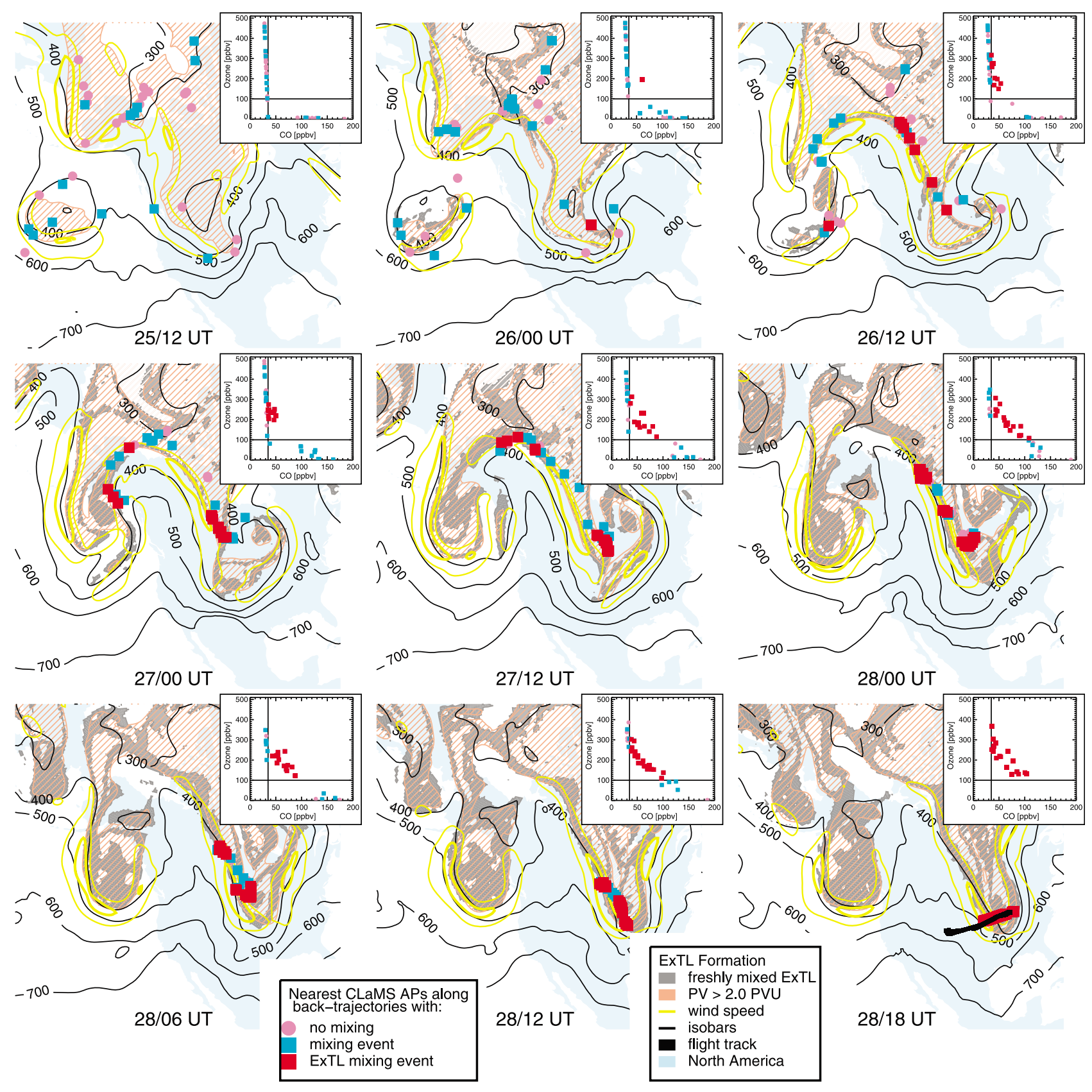

Figure 6. Formation of the freshly mixed part of the ExTL in the physical- and $\mathrm{CO}_{-} \mathrm{O}_{3}$-space. The physical space is shown as an isentrope at $\theta=310 \mathrm{~K}$. CLaMS was reinitialized on April 25th,12 UTC with no ExTL (using idealized $\mathrm{CO}-\mathrm{O}_{3} \mathrm{~L}$-shape correlation), indicated by the perfect separation of the stratosphere (orange hatched) from the troposphere (no shading). Nine snap shots at different model time steps are selected to show the developing ExTL in the next 3 days. The positions of the air parcels along the back-trajectories are shown as colored dots and squares, together with isobars (black) on $310 \mathrm{~K}$. When mixing at the nearest CLaMS air parcel occurred, the violet dots are switched to cyan squares. If, in addition, during such a mixing event, the composition of the air parcel changes from the L-shape type to a mixed correlation, the red color is used. These red parcels contribute to the modeled ExTL on April 28th, 18 UTC that was partially sampled during the GV flight.

out by Wohltmann and Rex [2009], may improve the quality of the Lagrangian mixing parametrization.

[30] Nevertheless, a strong inhomogeneity of Lagrangian mixing, both in time and space (according to CLaMS less than $15 \%$ of air parcels per day are affected by mixing), is the most pronounced difference compared to the Eulerian approach where numerical mixing is ubiquitous. Obviously, by switching off the mixing parametrization in CLaMS no ExTL at all will be formed from the L-shape initial CO-O correlation [Pan et al., 2006]. On the other hand, by 
including too much mixing (e.g. by degrading the spatial resolution of the model or by using too small value of $\gamma_{c}$ [see Konopka et al., 2004]), a much thicker ExTL will be produced with excessive mixing in the respective $\mathrm{CO}-\mathrm{O}_{3}$ correlation space (not shown). Nevertheless, the question how sensitive are our results with respect to the mixing parameters requires more work.

[31] Despite these shortcomings, our case study demonstrates that the tracer-tracer correlation is an effective tool to validate mixing schemes in the models which, reversely, can help to connect observed mixed air to the likely location and time of mixing events. We have also demonstrated a method of estimating the timescale of ExTL formation. The bulk of the ExTL in the direct vicinity of the jet is a result of mixing processes on a synoptic timescale of only few days. Considering all isentropes transecting the tropopause, the timescale of ExTL formation below the subtropical jet is much shorter compared with that on the isentropes above or crossing the jet (weeks versus months, Figure 5) This finding agrees fairly well with the results of the diffusive reconstruction [Legras et al., 2005] for $\mathrm{CO}-\mathrm{O}_{3}$ correlations observed in the sub-tropics [James and Legras, 2009] and, to some extent, supports the mixing parameterization in CLaMS.

[32] Furthermore, the ExTL formation process illustrated by this case study highlights the important role of mixing in accomplishing trace gas transport and STE. In this conceptual framework, the bi-directional STE processes are mixing processes across the ExTL or S-ExTL-T exchange processes. Because of the considerable thickness of the ExTL (up to few kilometers [e.g., Hoor et al., 2004]), the residence times of the air parcels in such a "no-ones land" are of the order weeks to months. Thus, diagnosing the net transport of tracer gases like ozone from the (pure) stratosphere to the (pure) troposphere or vice versa, i.e., the net stratosphere-totroposphere (STT) or troposphere-to-stratosphere (TST) tracer transport should take into account the existence of this layer (that is of course different from the mathematical surface defining the tropopause). This is a different manifestation of the concept that transport of mass is driven only by the flow velocity (and can therefore be diagnosed in terms of pure trajectory calculations) whereas, in addition to this advective flux, the gradient-driven and species-dependent diffusive fluxes (i.e. mixing) determine the tracer transport across the tropopause.

[33] Acknowledgments. We thank William J. Randel for many discussions motivating the authors to conduct this study and to write this paper. We are also grateful to Anne Kunz, Rolf Müller and two anonymous reviewers for their very helpful comments. Important support by the preparation of the final version of the manuscript was provided by Shawn Honomichl. The European Centre for Medium-Range Weather Forecasts (ECMWF) provided meteorological analyses for this study.

\section{References}

Birner, T., A. Dörnbrack, and U. Schumann (2002), How sharp is the tropopause at midlatitudes?, Geophys. Res. Lett., 29(14), 1700, doi:10.1029/ 2002GL015142.

Bowman, K. P., L. L. Pan, T. Campos, and R. S. Gao (2007), Observations of fine-scale transport structure in the upper troposphere from the Highperformance Instrument Airborne Platform for Environmental Research, J. Geophys. Res., 112, D18111, doi:10.1029/2007JD008685.
d'Ovidio, F., E. Shuckburgh, and B. Legras (2009), Local mixing events in the upper-troposphere lower-stratosphere: Part 1, detection with the Lyapunov diffusivity, J. Atmos. Sci., 60, 3678-3694.

Fischer, H., F. G. Wienhold, P. Hoor, O. Bujok, C. Schiller, P. Siegmund, M. Ambaum, H. A. Scheeren, and J. Lelieveld (2000), Tracer correlations in the northern high latitude lowermost stratosphere: Influence of crosstropopause mass exchange, Geophys. Res. Lett., 27(1), 97-100, doi:10.1029/1999GL010879.

Haynes, P., and E. Shuckburgh (2000), Effective diffusivity as a diagnostic of atmospheric transport: 2. Troposphere and lower stratosphere, J. Geophys. Res., 105, 22,795-22,810.

Hegglin, M. I., C. D. Boone, G. L. Manney, and K. A. Walker (2009), A global view of the extratropical tropopause transition layer from Atmospheric Chemistry Experiment Fourier Transform Spectrometer $\mathrm{O}_{3}, \mathrm{H}_{2} \mathrm{O}$, and CO, J. Geophys. Res., 114, D00B11, doi:10.1029/2008JD009984.

Hegglin, M. I., et al. (2010), Multimodel assessment of the upper troposphere and lower stratosphere: Extratropics, J. Geophys. Res., 115, D00M09, doi:10.1029/2010JD013884. [Printed 116(D3), 2011.]

Hintsa, E. J., et al. (1998), Troposphere-to-stratosphere transport in the lowermost stratosphere from measurements of $\mathrm{H}_{2} \mathrm{O}, \mathrm{CO}_{2}, \mathrm{~N}_{2} \mathrm{O}$ and $\mathrm{O}_{3}$, Geophys. Res. Lett., 25(14), 2655-2658, doi:10.1029/98GL01797.

Hoor, P., H. Fischer, L. Lange, J. Lelieveld, and D. Brunner (2002), Seasonal variations of a mixing layer in the lowermost stratosphere as identified by the $\mathrm{CO}-\mathrm{O}_{3}$ correlation from in situ measurements, J. Geophys. Res., 107(D5), 4044, doi:10.1029/2000JD000289.

Hoor, P., C. Gurk, D. Brunner, M. I. Hegglin, H. Wernli, and H. Fischer (2004), Seasonality and extent of extratropical TST derived from in-situ CO measurements during SPURT, Atmos. Chem. Phys., 4, 1427-1442.

James, R., and B. Legras (2009), Mixing processes and exchanges in the tropical and the subtropical UT/LS, Atmos. Chem. Phys., 9, 25-38.

Jeager, E. B., and M. Sprenger (2009), Vorticity, deformation and divergence signals associated with stratosphere-troposphere exchange, $Q . J . R$. Meteorol. Soc., 135, 1684-1696, doi:10.1002/qj.482.

Juckes, M., and M. McIntyre (1987), A high resolution, one-layer model of breaking planetary waves in the stratosphere, Nature, 328, 590-596.

Konopka, P., et al. (2004), Mixing and ozone loss in the 1999-2000 Arctic vortex: Simulations with the 3-dimensional Chemical Lagrangian Model of the Stratosphere (CLaMS), J. Geophys. Res., 109, D02315, doi:10.1029/2003JD003792.

Konopka, P., et al. (2007), Contribution of mixing to upward transport across the tropical tropopause layer (TTL), Atmos. Chem. Phys., 7(12), 3285-3308.

Konopka, P., J.-U. Grooß, G. Günther, F. Ploeger, R. Pommrich, R. Müller, and N. Livesey (2010), Annual cycle of ozone at and above the tropical tropopause: Observations versus simulations with the Chemical Lagrangian Model of the Stratosphere (CLaMS), Atmos. Chem. Phys., 10, 121-132.

Kunz, A., P. Konopka, R. Müller, L. L. Pan, C. Schiller, and F. Rohrer (2009), High static stability in the mixing layer above the extratropical tropopause, J. Geophys. Res., 114, D16305, doi:10.1029/2009JD011840.

Kunz, A., P. Konopka, R. Müller, and L. L. Pan (2011), Dynamical tropopause based on isentropic potential vorticity gradients, J. Geophys. Res., 116, D01110, doi:10.1029/2010JD014343.

Legras, B., I. Pisso, G. Berthet, and F. Lefevre (2005), Variability of the Lagrangian turbulent diffusion in the lower stratosphere, Atmos. Chem. Phys., 5, 1605-1622.

Marcy, T. P., et al. (2004), Quantifying stratospheric ozone in the upper troposphere with in situ measurements of HCl, Science, 304, 261-265, doi:10.1126/science. 1093418 .

McKenna, D. S., P. Konopka, J.-U. Grooß, G. Günther, R. Müller, R. Spang, D. Offermann, and Y. Orsolini (2002), A new Chemical Lagrangian Model of the Stratosphere (CLaMS): 1. Formulation of advection and mixing, J. Geophys. Res., 107(D16), 4309, doi:10.1029/2000JD000114.

Pan, L. L., W. J. Randel, B. L. Gary, M. J. Mahoney, and E. J. Hintsa (2004), Definitions and sharpness of the extratropical tropopause: A trace gas perspective, J. Geophys. Res., 109, D23103, doi:10.1029/ 2004JD004982.

Pan, L. L., P. Konopka, and E. V. Browell (2006), Observations and model simulations of mixing near the extratropical tropopause, J. Geophys. Res., 111, D05106, doi:10.1029/2005JD006480.

Pan, L. L., et al. (2007), Chemical behavior of the tropopause observed during the stratosphere-troposphere analyses of regional transport experiment, J. Geophys. Res., 112, D18110, doi:10.1029/2007JD008645.

Pan, L. L., et al. (2010), The Stratosphere-Troposphere Analyses of Regional Transport 2008 (START08) experiment, Bull. Am. Meteorol. Soc., 91, 327-342.

Pierrehumbert, R. T. (1991), Large-scale horizontal mixing in planetary atmospheres, Phys. Atmos. Fluids, 3A, 1250-1260. 
Scott, R., and J.-P. Cammas (2002), Wave breaking and mixing at the subtropical tropopause, J. Atmos. Sci., 28, 2347-2361.

Turner, J. S. (1973), Buoyancy Effects in Fluids, Cambridge Univ. Press, Cambridge, U. K.

Vogel, B., et al. (2011), Transport pathways and signatures of mixing in the extratropical tropopause region derived from Lagrangian model simulations, J. Geophys. Res., 116, D05306, doi:10.1029/2010JD014876.
Wohltmann, I., and M. Rex (2009), The Lagrangian chemistry and transport model ATLAS: Validation of transport and mixing, Geosci. Model Dev., 2, 153-173.

World Meteorological Organization (2003), Scientific assessment of ozone depletion: 2002, Global Ozone Res. Monit. Proj. Rep., 47, Geneva, Switzerland. 